Lexis Vol. XLIII (1) 2019: 87-116

\title{
De la lingüística a las aulas: ideologías en la educación peruana
}

\author{
Luis Andrade Ciudad \\ Virginia Zavala \\ Pontificia Universidad Católica del Perú
}

\section{RESUMEN}

Desde la noción de mercado simbólico y la visión de la práctica educativa como un instrumento de distinción social (Bourdieu 2002, 2008a, 2008b, 2013), nos preguntamos en este artículo por los vínculos entre la lingüística y la educación en el Perú. Para tal fin, analizamos las ideologías sobre el lenguaje reproducidas por José Jiménez Borja (1901-1982) y Luis Hernán Ramírez (1926-1997), dos intelectuales cuyos trabajos han tenido una importante influencia en la educación básica y en la instrucción universitaria peruanas, respectivamente. Nuestro examen muestra que la lingüística ha contribuido a generalizar en la educación peruana, por lo menos en parte, una visión jerárquica y discriminadora en términos socioculturales, sobre la base de ideologías que continúan vigentes en el ámbito hispánico, tanto en el sentido común como en el terreno académico. Sugerimos que una aproximación crítica e histórica a los nexos entre la lingüística y la educación puede enriquecer la articulación entre ambos campos en el Perú y en América Latina.

Palabras clave: ideologías lingüísticas, educación, lingüística sociocultural, estándar, bilingüismo 


\begin{abstract}
Taking into account the notion of symbolic market and the view of education as an instrument for social distinction (Bourdieu 2002, 2008a, 2008b, 2013), we approach in this paper the linkages between linguistics and education in Peru. With this view in mind, we analyse the language ideologies that José Jiménez Borja (1901-1982) and Luis Hernán Ramírez (1926-1997) displayed in their academic work. Both scholars have been influential in Peruvian basic education and university instruction, respectively. Our account shows that linguistics has taken a share in disseminating a hierarchic and discriminatory agenda in Peruvian schools and universities. Paramount for this process is a set of ideologies that are still prevailing in Hispanic countries, both in common sense and in the academia. We suggest that a critical and historical approach to the relationship between linguistics and education can enrich the articulation between both fields, in Peru and Latin America.
\end{abstract}

Keywords: language ideologies, education, sociocultural linguistics, standard, bilingualism

\title{
1. Introducción
}

En este artículo revisaremos las ideas de dos lingüistas peruanos sobre el campo educativo en dos momentos distintos de la historia del Perú y observaremos la continuidad de estas nociones en la sociolingüística hispánica contemporánea. Nos interesa ver cómo imaginan estos dos lingüistas, José Jiménez Borja y Luis Hernán Ramírez, el destino de los idiomas, las variedades y las formas de habla en la escuela y en la universidad, y cómo construyen la distinción entre grupos sociales a partir del lenguaje. Aprovecharemos para ello las nociones de Bourdieu (2002, 2008a, 2008b, 2013) sobre el mercado lingüístico y el campo educativo, así como otras aproximaciones a la educación como un espacio donde se produce diferencia a partir del lenguaje (Heller y Martin Jones 2001; García 2009). También nos servirá el concepto de ideología lingüística, entendida como un conjunto de representaciones sobre el lenguaje que median entre las formas de habla y la estructura social (Irvine y Gal 2000; Kroskrity 2010; Rosa y Burdick 2017; Woolard 2012). 
De manera específica, nos servirá la oposición que se plantea desde la pedagogía de la escritura entre una perspectiva "descriptiva" y una perspectiva "crítica" de la enseñanza del lenguaje (Ivanič y Moss 2004), así como el sistema de representación de procesos de Halliday (1994 [1985]), elaborado en el marco de la lingüística sistémico-funcional, y el modelo de representación de actores de van Leeuwen (1996), propuesto desde una rama del análisis crítico del discurso. De un modo más general, situamos nuestra indagación en el marco de la lingüística sociocultural (Bucholtz y Hall 2008; Bucholtz y Hall 2005), que aborda la relación entre el lenguaje, la cultura y la sociedad desde una perspectiva interdisciplinaria y recogiendo el aporte de diversos campos de estudio como la sociolingüística, la antropología lingüística y el análisis del discurso. ${ }^{1}$

Queremos observar cómo la lingüística ha contribuido a generalizar en la educación peruana, por lo menos en parte, una visión jerárquica y discriminadora en términos socioculturales. A pesar de su interés y su influencia, las obras de José Jiménez Borja y Luis Hernán Ramírez no han sido tomadas en cuenta en una reciente revisión de las ideas lingüísticas en el Perú (De los Heros 2012, cap. II); de ahí que nuestro examen tiene un interés histórico específico dentro de nuestra disciplina. Sin embargo, este ejercicio podría tener implicancias mayores, si consideramos que la sociolingüística surgió como una disciplina preocupada desde sus inicios por la justicia social y, de manera más específica, por la problemática del lenguaje en el campo educativo (p. ej., Gumperz 1982; Hymes 1974; Labov 1972).

Consideramos que la lingüística, en especial la de corte sociocultural (Bucholtz y Hall 2008; Bucholtz y Hall 2005), tendría mucho que aportar a este campo, siempre y cuando esté dispuesta a revisar

\footnotetext{
1 Este texto surge de una ponencia presentada en el coloquio internacional "El conflicto de las facultades. Sobre la universidad y el sentido de las humanidades”, realizado en la Pontificia Universidad Católica del Perú entre el 5 y el 8 de setiembre del 2017. Una versión preliminar, más sintética, de este artículo se publicará en las actas de dicho congreso. Agradecemos a Jorge Iván Pérez Silva y a Miguel Giusti, quienes nos alcanzaron valiosos comentarios para mejorar nuestro argumento.
} 
con ojo crítico sus propios presupuestos epistemológicos. Esto significa, entre otras cosas, trasladar la agencia de los individuos al escenario principal y reconocer que el poder constituye el motor de la producción lingüística. Como afirma Kress, "[t]odas las (inter) acciones lingüísticas han sido forjadas por las diferencias de poder de diversas maneras y no hay ninguna parte de la acción lingüística que pueda escapar a sus efectos” (2001: 35). Dicho en términos de Bourdieu, "[1]os efectos de dominación, las relaciones de fuerza objetivas del mercado lingüístico, se ejercen en todas las situaciones lingüísticas” (2002: 152).

\section{Educación, lenguaje y dominación simbólica}

Sabemos que la educación formal es un campo en el que se reproducen la sociedad y la cultura, pues, a través de ella, se instauran discursos hegemónicos que constituyen a los sujetos de una determinada manera (Apple 1987; Bourdieu y Passeron 1977; Giroux 1992). Examinar la educación a través del lente del lenguaje, enfocando la manera en que se construye la diferencia lingüística, no solo nos permite entender un poco más sobre las formas como opera el campo educativo sino también sobre los diversos caminos que sigue la construcción de la inequidad social. Los discursos sobre las diferencias lingüísticas en el campo educativo constituyen una forma de ejercer dominación simbólica y de jerarquizar a los grupos sociales en el mundo contemporáneo (Phillipson 1992).

La noción de campo, propuesta por Bourdieu, nos parece útil para estudiar el ámbito educativo porque pone el foco en la lucha de "agentes e instituciones, con fuerzas diferentes y según las reglas constitutivas” del espacio en cuestión (2002: 157). La noción tiene la ventaja de reconocer, a la vez, las presiones de las élites en el marco de una estructura social determinada, sin caer en un determinismo que anularía la potencial agencia de los grupos dominados. "Los que dominan el campo tienen los medios para hacerlo funcionar en provecho suyo", dice Bourdieu, "pero tienen que contar con la resistencia de los dominados”, apunta inmediatamente (2002: 157). 
La educación se encarga de reproducir la inequidad social a través de la construcción de lo que es valorado como lenguaje "legítimo" y mediante la identificación de quiénes cuentan como hablantes "normales". De hecho, el campo educativo participa de manera importante en la definición de lo que constituye el lenguaje autorizado. Todos los debates sobre quién debería hablar qué, cuándo y cómo, y sobre cómo son los diversos tipos de hablantes, constituyen, en verdad, discusiones sobre quién puede decidir qué cuenta como lenguaje legítimo (Heller y Martin-Jones 2001). Por lo tanto, las discusiones sobre qué tipo de prácticas lingüísticas deberían ser consideradas "buenas", "normales", "apropiadas" o "correctas" no son neutrales ni puramente técnicas, sino que se desarrollan en el marco de orientaciones ideológicas conectadas a intereses sociales, políticos y económicos. También resulta útil para pensar esta dinámica la noción de mercado lingüístico, definida por Bourdieu como un conjunto de parámetros (variables) de "formación de los precios de las producciones lingüísticas", parámetros que muchas veces funcionan para los actores sociales de manera infraconsciente (2002: 145).

Al privilegiar ciertas prácticas sobre otras, siempre hay intereses sociales en juego; hay algunos que ganan y otros que pierden con la representación de la realidad que se logra imponer. Todo ello significa que al ejercer control sobre el valor o el precio de los recursos y los usos lingüísticos —es decir, al lograr que algunas formas de hablar sean asignadas a un lugar en el continuo valorativo entre lo bueno y lo malo, lo apropiado y lo inadecuado, lo elegante y lo rústico-, los grupos dominantes controlan la producción y la distribución de otro tipo de recursos simbólicos y materiales. Nos referimos, por ejemplo, a lo que cuenta como conocimiento (recurso simbólico) o a los certificados y títulos que la escuela entrega al final de la formación (recursos materiales).

Cuando a un estudiante se lo tacha de "ignorante" por ser motoso, de "inferior" por ser quechuahablante, de "incapaz para poder pensar coherentemente" por no haber aprendido las convenciones de la escritura académica o por "hablar al revés", como muchas veces se dice de los hablantes de castellano amazónico, tiene 
menos oportunidades para adquirir otros recursos sociales porque, de entrada, sus producciones lingüísticas reciben un valor insuficiente en el mercado simbólico. Todo esto significa que los debates sobre normas y prácticas lingüísticas son, a fin de cuentas, discusiones sobre el control de recursos de otra índole; así, dichos debates están profundamente relacionados con la legitimación de relaciones de poder arbitrarias e inequitativas (Heller y Martin Jones 2001). El mercado simbólico está, pues, entrelazado de distintas maneras con la diversidad de mercados materiales que organizan el mundo social.

Todo lo anterior se vincula directamente con la noción de ideología lingüística, definida como "el sistema cultural de ideas sobre las relaciones entre lo social y lo lingüístico, junto con la carga de intereses morales y políticos” asociados (Irvine 1989: 225). Estamos, pues, ante representaciones sobre el lenguaje que median entre las formas de habla y la estructura social (Irvine y Gal 2000; Kroskrity 2010; Rosa y Burdick 2017; Woolard 2012). Esta noción, que ha cobrado un lugar prominente en la antropología lingüística y otros campos de la lingüística sociocultural, permite darnos cuenta de que las ideas sobre el lenguaje no son nunca simplemente sobre el lenguaje. Pongámoslo en otros términos: aunque los argumentos que los hablantes desarrollamos en torno a los recursos y a los usos lingüísticos en nuestra vida cotidiana — debates sobre formas de hablar o de escribir - puedan parecer muy "técnicos", en realidad, simbolizan conflictos sociales de orden económico, moral, racial y cultural que las personas no quieren asumir de forma más directa (Cameron 1995).

Después de todo, los debates en torno a la raza o a la cultura no son vistos como políticamente correctos en estos tiempos. Así, las diferencias lingüísticas actúan como un medio para aplicar procesos de categorización y jerarquización por raza, género o etnicidad que se encuentran implícitos en los debates en torno al lenguaje. Por lo tanto, las diferencias lingüísticas constituyen una forma de ejercer dominación simbólica precisamente porque sus fuentes concretas quedan enmascaradas. Mediante este tipo de procesos el común de las personas se convence de que las maneras de representar la 
realidad elaboradas por un grupo social son "naturales", "universales" y "objetivas", y de que ellas se corresponden con los intereses de la mayoría. Intentaremos a continuación revisar desde este marco conceptual las ideas lingüísticas de dos intelectuales peruanos: José Jiménez Borja y Luis Hernán Ramírez, para después evaluar su continuidad en el presente.

\section{José Jiménez Borja y el bilingüismo como problema}

En 1941, José Jiménez Borja, lingüista y educador, publicó en la importante revista Letras, de la Universidad Nacional Mayor de San Marcos (UNMSM), un artículo titulado "El problema del bilingüismo en el Perú”. Para situar el texto en el momento intelectual de la época, podríamos recordar que cinco años antes, en el ámbito de la lingüística, Pedro Benvenutto Murrieta había publicado su obra pionera El lenguaje peruano (1936). En un rango temporal más amplio, trece años antes, José Carlos Mariátegui había planteado que el "problema del indio" era, en realidad, el problema de la tierra, y ese mismo año, 1941, José María Arguedas publicaba Yawar Fiesta, mientras que Ciro Alegría ganaba el Concurso Latinoamericano de Novela con El mundo es ancho y ajeno, novelas ambas que, según la crítica literaria, se encontraban cerrando la fase del "indigenismo clásico" en el país (Escajadillo 1994).

Estaba entonces en declive el indigenismo clásico en la literatura; sin embargo, en el campo educativo, sectores identificados con esta corriente empezaban a influir con fuerza (Contreras 2014: 14). Fue en ese momento, cuando enseñaba Preceptiva y Metodología Castellana en la sección de Pedagogía de la Facultad de Letras de la UNMSM, que Jiménez Borja empezó a defender, más bien, desde el evolucionismo positivista, la idea de que el castellano estaba llamado a ser la lengua de la nación peruana y que las lenguas originarias no eran otra cosa que reliquias de un pasado destinado a extinguirse, "rosarios de manchas isoglósicas" desperdigadas por el país (2005 [1941]: 301). Hay en la obra de este autor, en primer lugar, la visión de que el manejo de dos lenguas en situación jerárquica, como en el 
caso del quechua frente al castellano, impide o retarda el desarrollo cognitivo y socioemocional de los estudiantes e impide la cohesión social. El bilingüismo se representa aquí como un elemento disociador en diferentes niveles de la realidad. Examinemos en sus propias palabras esta ideología. Al bilingüe, dice Jiménez Borja, sobre todo si es "de origen campesino y cultura rudimentaria":

todo tiene que serle hostil. Utiliza un instrumento de expresión que no le es propio y que lo siente áspero e insumiso y lo utiliza en un medio en que la acción de personas más sabias y poderosas comprime desde el punto de vista espiritual. Su incertidumbre será dolorosa, sus fallas le producirán confusión y cuando son objeto de burla, como a menudo pasa, le dejarán humillado y triste. De estas circunstancias se origina el complejo de inferioridad que descorazona por la sensación de que algo esencial falta para el cumplimiento de los cometidos sociales que a todos nos incumben (2005 [1941]: 300).

Es llamativo que Jiménez Borja no intente examinar ni cuestionar la legitimidad de las burlas experimentadas por el niño bilingüe. Las "fallas" se atribuyen al individuo y no se analiza, ni se invita a estudiar, la lógica que está detrás de los comportamientos lingüísticos estigmatizados, ni en términos individuales o cognitivos, ni mucho menos sociales (Cerrón-Palomino 2004). La modalidad categórica de este discurso se construye mediante verbos que expresan necesidad lógica ("[Al bilingüe] todo tiene que serle hostil”) y sobre todo mediante el uso del tiempo futuro: la incertidumbre del bilingüe "será dolorosa, sus fallas le producirán confusión y [...] le dejarán humillado y triste” (2005 [1941]: 300).

En este punto, el discurso de Jiménez Borja se asemeja al de algunos maestros universitarios ayacuchanos y cuzqueños de la actualidad que muestran posicionamientos alineados con los alumnos citadinos que se burlan de sus pares "de comunidades" por sus comportamientos "motosos", es decir, por la alternancia de timbre vocálico entre los pares /e, i/ y /o, u/ producida en el habla castellana como influencia del sistema fonológico del quechua y el aimara (Pérez Silva y Zavala 2010; Zavala y Córdova 2010, cap. 2). De un modo más general, notamos también aquí una corres- 
pondencia entre el discurso de Jiménez Borja y la "perspectiva descriptiva" presentada por Ivanič y Moss (2004: 214), dado que, desde esta visión, el educador concibe como inevitable que algunos tipos de lenguaje gocen de mayor estatus que otros y entiende que su rol consiste en proporcionarles a sus alumnos el mayor acceso posible a las formas de habla prestigiosas sin cuestionar la raíz del prestigio diferenciado. "El lamentable resultado de esto - señalan Ivanič y Moss (2004: 214) - es que, cuando a algunos estudiantes les va menos bien que a otros, se les culpa a ellos, no a los inflexibles valores de las instituciones educativas".

En un texto posterior, de 1955, titulado "Fines de la enseñanza del castellano y la literatura en el Perú", el autor recomienda qué hacer en el aula y fuera de ella con la "jerga criolla" que entonces empezaba a escalar socialmente difundiéndose en la música popular:

A los niños y al pueblo hay que hacerles notar lo que es palabra del cambiante galimatías a la moda y que pueden usar en sus juegos y charlas intrascendentes y lo que es palabra noble y general del idioma, capaz de ser entendida por todos y capaz de expresar, en este siglo y en el venidero, las altas concepciones del espíritu (Jiménez Borja 2005 [1955]: 283).

Es de notar, en la retórica del autor, en primer lugar, la asociación paternalista entre los niños y el pueblo; en segundo término, una llamativa combinación de adjetivos contrastantes por su valor positivo o negativo (cambiante-noble, intrascendente-general, alto-bajo) y una modalidad categórica que, además del tiempo futuro y de las implicaciones lógicas ya señaladas, privilegia los procesos verbales relacionales, en la terminología de Halliday (1994 [1985]). Estos procesos, basados típicamente en el verbo ser, introducen los atributos fijándolos al objeto calificado ("un instrumento de expresión que no le es propio", "lo que es palabra noble y general del idioma”, "Su incertidumbre será dolorosa"). Así, la cuidadosa redacción de Jiménez Borja construye un escenario en el que los mundos de una lengua y otra, de una cultura y otra, de unos hablantes y otros, quedan definitivamente enfrentados. El bilingüismo conduce, así, 
también al conflicto colectivo. Podemos resumir la primera ideología, entonces, como la visión del bilingüismo como un elemento disociador, tanto a nivel individual como social.

Una segunda ideología que queremos resaltar, y que está estrechamente ligada a la anterior, es la visión purista de que el contacto lingüístico conducirá necesariamente a la degradación, empobrecimiento y consecuente muerte de las lenguas. El contacto producirá, en primer lugar, formas de habla que, por razones inherentes a ellas, recibirán un valor inferior en el mercado simbólico. Al respecto, el autor nos dice lo siguiente en un fragmento que queremos citar de manera extensa debido a su interés:

Pero aun en las mismas campañas [campiñas, L. A. y V. Z.] de los Andes el quechua está mellado por la penetración castellanizante. Desde el Cuzco hacia el norte hay una declinación de su amplitud y de su fuerza. [...] La lucha no se manifiesta únicamente por la eliminación del quechua sino por la relajación morfológica y sintáctica de éste bajo la influencia del castellano. Así sucede con el quechua de Áncash y de Huánuco que ha tomado del castellano la conjunción $y$. En el "Apunchic Jesucristoc Chusco Evangeliocuna” o sea "Los Cuatro Evangelios" traducidos al quechua de los departamentos de Huánuco y Áncash por la Britis [sic] and Foreign Bible Society" en 1923, por razones de proselitismo, se condesciende con estas relajaciones que son un síntoma de agonía próxima. Las lenguas no mueren porque admiten el vocabulario de otras $y$, al contrario, como en el ejemplo del inglés moderno, éste puede ser un aspecto de su carácter imperial. Pero las lenguas sí mueren porque ceden en sus esencias morfológicas y sintácticas, reductos vertebrales de su organismo, aunque sea en detalles que aparentemente no tienen volumen como sus nexos y partículas (2005 [1941]: 302303) [énfasis del original].

Mucho habría que decir desde la teoría moderna del contacto de lenguas acerca de la creencia de que los "nexos y partículas” son algo así como "los últimos bastiones” del idioma. Al contrario de lo que Jiménez Borja pensaba, la investigación reciente ha mostrado que estos elementos se encuentran entre los que más frecuentemente se transfieren de una lengua a otra, casi tanto como los préstamos 
léxicos de los campos culturales más flexibles al contacto (Matras 2009). No queremos caer, sin embargo, en la "posición cómoda" del ahistoricismo, advertida con prudencia por Cerrón-Palomino, que implicaría apoyarse "en los dictados contemporáneos de la psicología, la educación, la lingüística y las ciencias sociales” para refutar las afirmaciones del lingüista y educador "sin atender al momento (hegemonía de las tesis behavioristas) y al contexto (de la posguerra) en que ellas fueron formuladas" (2004: 27). ${ }^{2}$

Es más interesante examinar en sus propios términos el repertorio organicista utilizado por Jiménez Borja. El autor representa metafóricamente la lengua como el cuerpo humano, y establece una equivalencia entre las vértebras de la columna y ciertos elementos del lenguaje, las "bisagras" de la sintaxis, podríamos decir. Desde una perspectiva que asume el monolingüismo como el estado natural, resulta inevitable que el bilingüismo desemboque en un conflicto que concluirá con el triunfo de uno de los códigos sobre el otro, y, por supuesto, será el código empobrecido y degradado el que terminará vencido, como un cuerpo inerte que debió soportar demasiado peso. El lingüista y educador proyectará con la indiferencia del científico natural este desenlace. Lejos de ser fenómenos históricos — sujetos, por tanto, a la acción de los hablantes y a los avatares de los procesos y conflictos sociales-, la sustitución y la opresión de las lenguas se representan como asuntos determinados por leyes universales, como los procesos biológicos básicos del cuerpo humano:

Éstas —nos dice- no son apreciaciones sentimentales, originadas por afán hispanizante o por menosprecio a los valores terrígenos. Son simples observaciones objetivas, basadas en la ciencia idiomática y en la realidad peruana (2005 [1941]: 303).

\footnotetext{
2 Cerrón-Palomino hace un importante apunte histórico que ayuda a entender la fuerza que cobraba entonces la ideología de "una lengua-una nación” en el contexto de posguerra: "Es la época en que los países europeos (Inglaterra, Francia, España) se debatían en la forja y consolidación de sus lenguas nacionales, negando toda presencia a ciertas lealtades idiomáticas que persistían, y aún persisten, desafiando soluciones hegemónicas centralistas" (2004: 27).
} 
Podemos formular, así, la segunda ideología como aquella que establece, con la fuerza de una ley, que en una situación de bilingüismo jerarquizado, como el establecido entre el quechua y el castellano, es la "lengua de cultura", el castellano, la que afectará la "esencia íntima" del código subordinado, degradándolo, y se impondrá sobre él. En un país como el Perú de los años cuarenta, que, según el censo de la época, todavía mostraba la presencia de una mayoría de hablantes monolingües en quechua, aimara y lenguas amazónicas, el diagnóstico de Jiménez Borja tenía que desembocar en la propuesta violenta de la castellanización acelerada. ${ }^{3}$

"Felizmente el Perú marcha rápidamente al porvenir" es su categórica conclusión, porque "el progreso no puede detenerse por más que avance con la lentitud de un glaciar” (2005 [1941]: 302). La tarea educativa, desde esta mirada, consistirá en ayudar al estudiante a pasar lo más rápido posible al castellano, abandonando el cauce perturbador de su lengua originaria. Difícilmente encontraremos una expresión más clara, en el terreno lingüístico, de que la escuela en el Perú ha constituido una "tarea civilizadora" para "redimir al indio" e incluirlo violentamente en el proyecto nacional, como ha argumentado persuasivamente el historiador Carlos Contreras (2014).

\section{Luis Hernán Ramírez y la construcción ideológica del estándar}

Unas décadas después, en 1969, Luis Hernán Ramírez escribió un manual titulado Estructura y funcionamiento del lenguaje, dirigido "a los estudiantes que en la universidad y en los centros superiores de estudios se acercan al conocimiento riguroso y serio sobre el lenguaje usado a diario" (1969: 11-12). Para situar el texto brevemente en la historia cultural y política del país, diremos que ese era el mismo año en que el entonces gobernante, el general Juan Velasco Alvarado, promulgaba la ley de reforma agraria; el dirigente campesino Hugo

\footnotetext{
3 En el caso del quechua, según el censo de 1940, la mitad de los peruanos decía hablarlo en ese entonces (Pozzi-Escot 1987, citada por Chirinos 1998: 455, nota 5).
} 
Blanco se encontraba preso en la isla de El Frontón por su participación en las tomas de tierras de La Convención, en el Cuzco; Mario Vargas Llosa publicaba Conversación en La Catedral; la pintora Tilsa Tsuchiya regresaba de su formación en París y Arguedas escribía El zorro de arriba y el zorro de abajo, mientras maduraba la decisión de quitarse la vida. José Jiménez Borja, por su parte, ejercía la docencia en las facultades de Letras y de Pedagogía en la UNMSM, donde también se encontraban ya activos los lingüistas Alberto Escobar e Inés Pozzi-Escot, y Luis Jaime Cisneros publicaba Lengua y enseñanza, una recopilación de artículos que tuvo menos difusión nacional que el libro que estamos comentando (Cisneros 1969). ${ }^{4}$

Siguiendo a Saussure y el paradigma de la lingüística estructural, Ramírez separa la "lingüística interna" de la "lingüística externa" y propone la primera como el objeto principal de la lingüística. La "lingüística externa" correspondería al "estudio del lenguaje tomando en cuenta todo aquello que es extraño a su organismo" (1969: 54) [énfasis nuestro]. En sus palabras:

La verdadera lingüística es fundamentalmente lingüística interna y descarta, en principio, todas las cuestiones exógenas en el estudio de la lengua propiamente; sin embargo, el tratamiento de los factores externos ha sido siempre muy útil y fructífero para el conocimiento del organismo lingüístico interno (1969: 54).

Como veremos, el autor desarrolla un paradigma que impide aproximarnos a los vínculos entre el lenguaje y la reproducción de la desigualdad social, pues la agencia de los sujetos queda en un segundo plano. Es más, en el marco de este paradigma y todavía bajo la influencia de las ideologías románticas del siglo XIX, la lengua se analoga con un organismo, como si se tratara de un cuerpo vivo y autónomo que se desarrolla al margen de sus hablantes.

\footnotetext{
4 El vínculo entre Jiménez Borja y Ramírez se adivina estrecho a nivel personal si tomamos en cuenta que el primero reseñó un poemario del segundo (Jiménez Borja 1973). Cuánto de las concepciones del estándar propaladas por el alumno Ramírez se debe a la influencia intelectual del maestro Jiménez Borja, con el que seguramente estudió en la UNMSM, es una pregunta que podría plantearse y que no abordaremos aquí.
} 
A la fecha, el libro de Ramírez cuenta con siete ediciones y es utilizado en muchas universidades en el Perú, sobre todo en aquellas donde el autor enseñó durante su carrera docente: la Universidad Nacional San Cristóbal de Huamanga, la Universidad Nacional de Ica, la Universidad Nacional Mayor de San Marcos y la Universidad Nacional "Enrique Guzmán y Valle”, la Cantuta. A diferencia de Jiménez Borja, su interés central no radica en el tema del bilingüismo y el contacto de lenguas. Sin embargo, en algunas de las páginas del manual se alinea con las ideas del autor mencionado y representa el monolingüismo como la norma y el bilingüismo como un problema o como la desviación de una situación supuestamente no marcada: "[E]l contacto de lenguas o lenguas en contacto es un fenómeno que ocurre cuando un grupo humano se ve obligado por circunstancias muy diversas a utilizar dos o más lenguas" (1969: 163-164, énfasis nuestro).

Su perspectiva "descriptiva" lo lleva a presentar la situación de bilingüismo en el Perú como natural y no como producida a partir de relaciones de poder: la diglosia, afirma, es un tipo de bilingüismo "que se da en países de América Latina donde coexisten el español como lengua oficial hablada por las clases dominantes y las lenguas indígenas habladas solo por los campesinos y pobladores rurales con escasa instrucción" (1969: 165). En lugar de presentar los hechos como construcciones sociales surgidas de luchas de poder (y siempre con posibilidad de cambiar), el autor opta por una actitud políticamente neutral a favor de las cosas "tal como son", como si se tratara de situaciones naturales e inevitables.

Esta invisibilización del poder y de los antagonismos no solo se aprecia en relación al tratamiento del bilingüismo, sino también cuando aborda un tema complejo como lo son el estándar y la corrección idiomática. Veremos que al asumir los hechos como naturales y dados, la lingüística puede convertirse en cómplice de la reproducción de la desigualdad social; en fuente de distinción, en términos de Bourdieu. Comencemos con la siguiente cita del autor:

Los nacidos en hogares privilegiados, en cuanto a riqueza, tradición familiar y educación se convierten en hablantes de lo que reconocemos 
corrientemente como "buen lenguaje", se trata del lenguaje general que los lingüistas prefieren llamar lenguaje estándar, en cambio los menos afortunados, económica, social y culturalmente, se convierten en hablantes natos de un "mal lenguaje" al que se le ha dado el nombre de lenguaje subestándar (Ramírez 1969: 129).

En este extracto, el autor coloca los términos "buen lenguaje" y "mal lenguaje" entre comillas probablemente para transmitir que no hay nada naturalmente bueno o malo en las formas lingüísticas y que la denominación proviene de criterios sociales (“externos”). Sin embargo, esto lo hace en el marco de una reificación de las relaciones de poder ejercidas en la sociedad, que habrían producido situaciones de desigualdad. Así, por ejemplo, asume como dado el privilegio de ciertos hogares y de ciertas personas. Al utilizar "privilegiado" y "menos afortunado" como atributos de los hogares, fija la relación entre el objeto y la característica, como si se tratara de algo natural. Además, aunque coloca los términos arriba mencionados entre comillas, sostiene que las personas "se convierten en hablantes" de un buen o de un mal lenguaje. Este tipo de proceso de corte más conductual, según la taxonomía de Halliday (1994 [1985]), construye una representación según la cual las personas hablan bien o mal como consecuencia del hogar donde nacen y la caracterización de "lo bueno" y "lo malo" no es producto de relaciones de poder.

Uno de los conceptos discutidos por Ramírez que se ha extendido ampliamente en las aulas de la educación superior es la existencia de "niveles del uso lingüístico". Estos niveles serían el superestándar, el estándar y el subestándar. En su presentación de estos niveles, el autor reproduce una ideología lingüística en la que se borran las relaciones de poder que han asociado algunas maneras de usar el lenguaje con formas prestigiosas y más valoradas. Esto se logra naturalizando estos fenómenos como si se tratara de objetos. Veamos algunos ejemplos:

1. Las formas estándar del lenguaje gozan de prestigio (1969: 131).

2. El empleo de una forma de lenguaje [...] retrata al individuo de cierta manera y lo incorpora a una clase o jerarquía (1969: 170). 
3. El dialecto supone un espíritu local y de campanario, un cariño a lo nativo y atención a lo peculiar e inmediato. En cambio, la lengua general tiene espíritu de universalidad, preferencia por el cosmopolitismo y aspira a una validez superior (1969: 141).

4. El usuario de una lengua tiene ante sí una norma de la cual no puede apartarse impunemente (1969: 169).

Esta ideología lingüística, como una forma específica de representar la realidad, enfatiza la atribución de ciertas características al estándar o a la "lengua general”. Tal como en el caso de Jiménez Borja, se enmarca en una estrategia retórica en la que priman los procesos relacionales, pero, además, en este caso, no aparecen sujetos responsables de acciones concretas. En el primer ejemplo, el "prestigio" se vincula con "las formas estándar" a partir del verbo gozar, como si el prestigio fuera un atributo natural de la variedad mencionada. En el segundo ejemplo, el verbo retrata cumple una función similar, pues conecta "el empleo de una forma de lenguaje" con un lugar en la estructura social, como si estuviéramos ante una relación natural.

En el tercer ejemplo, los verbos supone y tiene también funcionan como procesos relacionales, que atribuyen las características mencionadas a las formas lingüísticas. El verbo aspira va un poco más allá al animizar la "lengua general” y atribuirle un proceso mental. Finalmente, en el cuarto caso, se vincula al "usuario de una lengua" con una norma a partir del proceso relacional tiene, como si la norma fuese una característica intrínseca del sujeto y no una imposición de fuera. Como afirma Cameron (1995), debemos abandonar una perspectiva determinista de la normatividad y preguntarnos de dónde vienen las normas lingüísticas y cómo estas se interiorizan en los hablantes. Los ejemplos anteriores encajan en una perspectiva descriptiva del lenguaje, que representa la variedad, lo apropiado y el registro como si fueran fijos y, por lo tanto, incuestionables, y que sugiere que es natural y justo que la realidad sea de esa manera. Según Ivanič y Moss (2004), este enfoque induce a los estudiantes a que acepten las cosas como son, pues se asume como correcto e inevitable que ciertos tipos de lenguaje tengan más prestigio que otros. 
Además de naturalizar y reificar la existencia de formas con prestigio y formas sin prestigio, Ramírez reproduce una segunda ideología lingüística que también niega las relaciones de poder y los antagonismos. En virtud de esta segunda ideología, define el estándar o las formas concebidas como prestigiosas apelando al consenso y a la participación democrática a partir del uso de formas indeterminadas y colectivas. De esta manera, construye el estándar como producto de la voluntad de todos y no de luchas de poder que involucran a diferentes grupos de actores sociales con recursos simbólicos y materiales desigualmente distribuidos; es decir, actores con lugares distintos, jerarquizados, en el mercado lingüístico. Veamos los siguientes ejemplos sobre la corrección idiomática:

1. Preocupación natural y cotidiana en el manejo de un idioma es la corrección o sujeción del uso idiomático a un conjunto de preceptos adoptados y rigurosamente observados por los miembros de una comunidad lingüistica (1969: 169).

2. El uso correcto de la lengua implica una norma exigida por la sociedad (1969: 170).

3. Adecuación externa de la expresión a las formas socialmente admitidas como buenas (1969: 172).

4. El error en el lenguaje equivale a una desviación de lo que la comunidad espera como correcto (1969: 172).

5. Se constituyen así los llamados criterios de corrección que justifican el empleo de tales o cuales formas expresivas previamente reconocidas como de mayor prestigio por el consenso de la comunidad hablante (1969: 170).

En los ejemplos anteriores, los actores que son responsables de dictaminar el "uso correcto de la lengua" son denominados de forma colectiva e indeterminada. De esta manera, se hace alusión a "los miembros de una comunidad lingüística", "la sociedad", "formas socialmente admitidas", "la comunidad" o "la comunidad hablante". Así, es este actor social indeterminado el que observa, exige, admite, espera y reconoce. En el último ejemplo, el actor que reconoce las formas expresivas como de mayor prestigio está 
incluso despersonalizado a partir de la nominalización "consenso de la comunidad hablante", lo que oculta de manera más fuerte las relaciones de poder implicadas en la delimitación del estándar. Esta representación ideológica construye la ilusión de un acuerdo en torno al estándar que niega los antagonismos y sustenta formas de dominio a través del consenso y no de medidas coercitivas. Las relaciones de poder han generado una "verdad" en torno a la variedad estándar, una verdad que ya es parte del sentido común y que es justificada y defendida por los propios actores que resultan perjudicados por ella. Se trata de un claro ejemplo de la premisa ideológica que presenta el interés propio como el interés común y general de todos los miembros de la sociedad (Marx y Engels 1968: 53).

Sabemos, sin embargo, que la variedad estándar no se decide por consenso y que tampoco es hablada por la mayoría de la población. Es más, no es difícil darnos cuenta de que son los sectores privilegiados los que manejan la variedad estándar, que la gran mayoría no la conoce, que no necesariamente permite entendernos entre todos, que constituye la variedad ideal precisamente porque es la que representa a los sectores de élite y que estos últimos, y no todos, son los que deciden qué es estándar o no y qué forma es la apropiada para los diferentes contextos (Siegel 2006; Milroy y Milroy 1999; Flores y Rosa 2015; Rosa 2016).

Una tercera ideología lingüística reproducida por Ramírez y también muy extendida en la lingüística dominante se refiere al discurso de "lo apropiado", que ha sido definido como una categoría ideológica al servicio de un orden sociolingüístico asociado a ciertos intereses (Fairclough 1995; Flores y Rosa 2015). En el manual que estamos revisando, los significantes apropiado, adecuado y acomodar se usan de modo constante. Veamos los siguientes ejemplos:

1. En general la lengua coloquial es una modalidad de la lengua estándar apropiada para todas las circunstancias no formales (1969: 133). 
2. Al lenguaje como a otras convenciones propias de la convivencia humana bay que emplearlo adecuándolo a ciertas exigencias habituales, a ciertas normas de prestigio social que certifican una buena educación (1969: 170).

3. Las personas deben acomodar su actuación lingüística a la competencia de sus oyentes o lectores (1969: 169).

En los ejemplos anteriores, se reifica la asociación entre formas lingüísticas particulares y tipos de contextos, como si se tratara de conexiones naturales. En el primer caso, la frase "apropiada para todas las circunstancias no formales" constituye un atributo que se adjudica a la "lengua coloquial" a partir de un proceso relacional con el verbo ser. En el segundo caso, el significante adecuándolo aparece en una construcción modal deóntica que sitúa el uso del lenguaje según los contextos como una obligación que hay que acatar. El último ejemplo presenta algo parecido a partir del verbo modal deber. Es curioso, sin embargo, que el deber de acomodar la actuación lingüística no se vincula esta vez con el contexto sino con "la competencia de sus oyentes o lectores". Si analizamos este fraseo, podemos deducir que se presupone que los oyentes o lectores son quienes usan las formas estándares y no quienes emplean formas construidas como "incorrectas".

Algunos investigadores han planteado que este discurso de "lo apropiado" no hace sino reproducir los arreglos ideológicos dominantes, pero con un nuevo discurso a favor del "respeto" por los estudiantes. Como bien ha anotado Leeman (2005), decirles a los estudiantes que sus variedades lingüísticas son correctas, pero, a la vez, inapropiadas para el contexto académico y profesional naturaliza el tratamiento desigual de las variedades lingüísticas y de sus hablantes, y disfraza la prescripción lingüística como descripción inocente o formulada desde lo políticamente correcto. La asociación entre lengua y contexto es también parte de un campo de negociación, y la división entre lo apropiado y lo inapropiado no puede naturalizarse como si se tratara de un hecho de la realidad fijado de una vez y para siempre. 


\section{Reflexiones finales}

No queremos dejar la impresión de que los autores examinados han tenido obras marcadas solamente por ideologías excluyentes y discriminadoras. Ambos cuentan con una producción intelectual amplia y valiosa, de la cual nosotros hemos revisado solamente un fragmento. Ramírez, por ejemplo, fue autor de uno de los pocos estudios panorámicos del español amazónico con que la dialectología peruana cuenta actualmente (Ramírez 2003). Jiménez Borja, por su parte, fue uno de los principales estudiosos de la poesía de Góngora en nuestro medio, y su ejercicio docente en la UNMSM contribuyó a formar generaciones de lingüistas y educadores destacados, despertando vocaciones por el estudio del español peruano y de las lenguas indígenas. ${ }^{5}$ Hay que reconocer, sin embargo, que Jiménez Borja y Ramírez también han propagado ideologías lingüísticas que han contribuido a construir la distinción y la jerarquía social en nuestro país. Esta influencia se traduce en la producción de manuales escolares usados en los años cuarenta y cincuenta, por parte de Jiménez Borja, y de manuales universitarios empleados desde la década de 1970 hasta hoy, por parte de Ramírez. ${ }^{6}$

La revisión efectuada muestra que una disciplina como la lingüística ha tenido una oportunidad efectiva de influir en el campo educativo a través de sus discursos especializados. Tanto Jiménez Borja como Ramírez aprovecharon este espacio, tal vez involuntariamente, para reproducir ideologías que contribuyeron a generalizar, por lo menos en parte, una visión jerárquica y discriminadora en términos socioculturales.

\footnotetext{
5 Martha Hildebrandt le dedicó su tesis doctoral sobre el español de Piura (Hildebrandt 1949) y Rodolfo Cerrón-Palomino ha recordado con gratitud los ejercicios de segmentación y análisis gramatical a los que "don José” los "sometía” a él y a sus compañeros en el curso de Sintaxis Española (2004: 20).

6 Obtener una visión más completa de la interacción entre la obra de Jiménez Borja y el campo educativo implicaría revisar estos manuales y analizar en qué medida las ideas desplegadas en sus artículos teóricos se traducen en los contenidos y actividades que proponía trabajar con los alumnos. Véase, por ejemplo, Jiménez Borja (1940). Entrevistas con maestros jubilados también serían útiles para recuperar parte de esta historia de la educación lingüística peruana.
} 
En este orden de ideas, cabe preguntarse cuánto de las concepciones revisadas persiste hasta hoy. Si bien las concepciones sobre el bilingüismo han variado mucho en las últimas décadas, y el sentido común se orienta actualmente hacia una valoración positiva del manejo de distintas lenguas, tanto a nivel individual como social, es posible plantear que la visión del bilingüismo como un problema en lugar de una fuente de recursos subsiste en alguna medida, pero no para el bilingüismo de élite sino para el que caracteriza a los hablantes de lenguas originarias que manejan también el castellano.

Es relevante en este punto la distinción planteada por el lingüista y educador Luis Enrique López entre el "bilingüismo de los unos y de los otros" (López 1990), haciendo referencia al tratamiento desigual que se les da en el Perú, y en otros países multilingües de América Latina, a los hablantes de castellano que manejan, además, una lengua como el inglés, el alemán o el italiano, por un lado, y a aquellos otros que son bilingües entre castellano y quechua, aimara, asháninka, shipibo o awajún. La educación intercultural bilingüe como una educación compensatoria y remedial que no sería necesaria cuando los niños y niñas ya saben castellano posiciona a la lengua originaria como un problema que hay que "superar" y constituye una buena ilustración de este "otro bilingüismo" subvalorado.

Por otra parte, significantes como quechuañol y aimarañol, muy usados en el sur central andino y el sur andino, revelan la vigencia de concepciones puristas y denigratorias de los resultados del contacto de lenguas.? En la Amazonía se ha registrado, asimismo, la frase nominal castellano bola-bola para hacer referencia al español aprendido como segunda lengua por los hablantes de lenguas indígenas (ver Andrade, Delgado, Frisancho y Napurí 2017 para el caso del bora). Asimismo, el discurso de algunos maestros escolares revela una preocupante falta de conciencia crítica sobre las jerarquías lingüísticas históricamente construidas que dichos significantes expresan. Tenemos evidencia suficiente para pensar, entonces, que

\footnotetext{
Cf. Firestone 2017: 79-80 y las referencias citadas allí para quechuañol; para aimarañol, visita de campo a Puno de Andrade (5-8/11/2015).
} 
el rechazo del bilingüismo y de usos lingüísticos que son resultado del contacto se sigue empleando en el campo educativo peruano para construir la diferencia; es decir, para jerarquizar y oprimir a distintos grupos de hablantes o, en términos más específicos, para racializarlos.

Las concepciones revisadas en Jiménez Borja también tienen continuidad en una sociolingüística hispánica comprometida con un paradigma funcional-estructural que sigue sosteniendo nociones como diglosia, alternancia de códigos, hablante nativo, semilingüismo, bilingüismo coordinado, entre muchas otras, ya cuestionadas en una bibliografía contemporánea que concibe el bilingüismo como una práctica social e ideológica (García 2009; Heller 2007). Entre otros aspectos, este paradigma funcional-estructural entiende las lenguas como sistemas completos y delimitados; el bilingüismo coordinado como dos hablantes monolingües yuxtapuestos; el bilingüismo totalmente balanceado como el ideal a alcanzar; la existencia de una relación natural entre lengua, cultura e identidad; y los ámbitos sociales como capaces de determinar la actuación lingüística sin pasar por la agencia de los hablantes (Moreno Fernández 1998). De esta manera, se reproduce una perspectiva del déficit en la manera de observar y representar ciertas prácticas lingüísticas y un discurso de lo apropiado que no cuestiona las relaciones de poder.

En cuanto a las ideologías asociadas al estándar, las cosas no parecen ser distintas. De los Heros ha mostrado recientemente que en algunos textos usados en la escuela peruana se sigue asociando la noción de barbarismo con rasgos regionales de castellano, alejados de las formas prestigiosas (2012: 142). Por otro lado, la lingüística actual también ha construido una representación ideológica en torno al estándar como aquella variedad socialmente aceptada, como la más adecuada para los contextos formales de uso, como la forma socialmente preferida y como aquella que ha surgido a partir de un acuerdo social más o menos tácito con el fin de entendernos perfectamente entre todos. Incluso se ha planteado que son "los hablantes", nombrados de forma general e indeterminada, los que 
pueden decidir qué es estándar y qué no, y qué formas de habla son adecuadas para qué tipo de contexto (Bernárdez 2004).

Por lo tanto, aunque los lingüistas defendemos la idea de que el estándar constituye una variedad que no es intrínsecamente superior a otras (y Ramírez también se alinea con esta postura), no cuestionamos de modo suficiente la idea común de que esta variedad ha sido elegida por consenso y de forma democrática, de que todos tenemos las mismas oportunidades de aprenderla si es que nos esforzamos lo suficiente y de que ya no seremos discriminados y ascenderemos socialmente si decidimos usarla en los contextos donde es apropiado hacerlo (Bernárdez 2004). ${ }^{8}$ Esto va de la mano, nuevamente, con una perspectiva de "lo apropiado" que ha desarrollado la sociolingüística de corte más "liberal" en las últimas décadas con relación a la variedad estándar y a la literacidad académica. Desde este paradigma, la idea es enseñar a usar las formas "apropiadas" en los momentos "apropiados", en un marco que adopta las convenciones dominantes sobre qué es lo adecuado como naturales y necesarias. Una sociolingüística de este tipo no hace sino reproducir los arreglos ideológicos hegemónicos, pero con un discurso a favor del "respeto" por los estudiantes.

Nosotros pensamos que la educación lingüística no puede reducirse a un entrenamiento de habilidades para que los estudiantes utilicen formas lingüísticas particulares en los contextos "apropiados". También pensamos que esta formación debería ser más flexible y menos purista en relación con los resultados del contacto de lenguas, fomentando en el aula el despliegue creativo de los diferentes recursos lingüísticos que los estudiantes manejan y observando el bilingüismo como una fuente de oportunidades abierta a la negociación y a la acción de los hablantes y de sus agrupaciones a través de la historia. Impulsar, en cambio, las ideologías dominantes sobre el estándar y sobre el bilingüismo nos haría cómplices

\footnotetext{
8 Véase Mesía (2016: 170-174) para una descripción detallada de la ideología de la “igualdad de oportunidades" asociada al estándar en las concepciones de estudiantes de colegios públicos limeños.
} 
de posiciones a partir de las cuales se normalizan o legitiman representaciones políticas que refuerzan la distinción y la discriminación de diversas formas de habla y de los grupos que las usan. Lo que necesitamos es una perspectiva crítica, lo que implica representar la variedad de códigos y recursos lingüísticos, lo apropiado y el registro como elementos abiertos al cuestionamiento y al cambio. Después de todo, son las relaciones de poder, y no la voluntad del individuo o las leyes naturales, las que están en juego en la desaparición de las lenguas, en la elección del estándar y en la vergüenza que sienten muchas personas al hablar de una determinada manera.

Los lingüistas hemos enfatizado demasiado que la lingüística es descriptiva y no prescriptiva, desde una dicotomía que, según Cameron (1995), corre el riesgo de reproducir una división entre "hechos objetivos" (los supuestamente descritos por los lingüistas) y juicios de valor "subjetivos" (aquellos emitidos "erróneamente" por los hablantes comunes). Tal vez debemos empezar a asumir críticamente nuestros propios posicionamientos, así como la forma en que hemos enfocado nuestro objeto de estudio en el marco de ideologías particulares. Revisar la propia historia de nuestra disciplina en diálogo con el campo educativo puede ser una manera productiva de empezar esta tarea.

\section{Referencias bibliográficas}

Andrade Ciudad, Luis, Guillermo Enrique Delgado, Susana Frisancho y Andrés NAPURí

2017 "Introducción: un acercamiento interdisciplinario a la historia de vida de Hilario Díaz Peña”. En No estoy viajando callado. Historia de vida de un maestro bora. Hilario Díaz Peña. Lima: Fondo Editorial de la Pontificia Universidad Católica del Perú, 9-65.

Apple, Michael

1987 Educación y poder. Madrid: Paidós.

Benvenutto Murrieta, Pedro Manuel

1936 El lenguaje peruano. Lima: Sanmartí. 
Andrade y Zavala • De la lingüística a las aulas: ideologías en la educación peruana 111

BERNÁRdEZ, Enrique

2004 “De lenguas, dialectos, idiomas, hablas, jergas”. ¿Qué son las lenguas? Madrid: Alianza Editorial, 33-60.

Bourdieu, Pierre

2002 "El mercado lingüístico". En Sociología y cultura. México: Grijalbo / Conaculta, 143-158.

2008a Capital cultural, escuela y espacio social. Buenos Aires: Siglo XXI.

2008b ¿Qué significa hablar? Economía de los intercambios lingüisticos. Madrid: Akal.

2013 La nobleza de estado: educación de élite y espiritu de cuerpo. Buenos Aires: Siglo XXI.

Bourdieu, Pierre y Jean Claude Passeron

1977 La reproducción. Barcelona: Laia.

Bucholtz, Mary y Kira Hall

2005 "Identity and interaction: A sociocultural linguistic approach". Discourse Studies. 7, 585-614. https://doi. org/10.1177/1461445605054407

2008 "All of the above: New coalitions in sociocultural linguistics". Journal of Sociolinguistics. 12, 4, 401-431. https://doi. org/10.1111/j.1467-9841.2008.00382.x

Cameron, Deborah

1995 Verbal bygiene. Londres: Routledge. https://doi. org/10.4324/9780203991695

Cerrón-Palomino, Rodolfo

2004 "Don José Jiménez Borja y el castellano peruano". En Actas del Simposio "Centenario de José Jiménez Borja. Descripción y enseñanza del español”. Ed., Luis Miranda Esquerre.. Lima: Universidad Ricardo Palma, 19-29.

Chirinos, Andrés

1998 "Las lenguas indígenas peruanas más allá del 2000”. Revista Andina. 32, 453-479.

Cisneros, Luis Jaime

1969 Lengua y enseñanza. Lima: Studium.

Contreras, Carlos

2014 "Maestros, mistis y campesinos en el Perú rural del siglo XX”. En Modernidad y educación en el Perú. Serie Diversidad 
Cultural 9. Carlos Contreras y Patricia Oliart.. Lima: Ministerio de Cultura, Viceministerio de Interculturalidad. Modernidad y educación en el Perú. Serie Diversidad Cultural 9. Consultado: S/f. <https://centroderecursos.cultura.pe/ sites/default/files/rb/pdf/ModernidadyeducacionenelPeru. $\mathrm{pdf}>$.

De los Heros, Susana

2012 Utopía y realidad: nociones sobre el estándar lingüistico en la esfera intelectual y educativa peruana. Madrid / Frankfurt / Lima: Iberoamericana / Vervuert / Instituto de Estudios Peruanos. https://doi.org/10.31819/9783954870202

Escajadillo, Tomás G.

1994 La narrativa indigenista peruana. Lima: Amaru.

FAIRCLOUGH, Norman

1995 "The appropriacy of 'appropriateness"”. En Critical Discourse Analysis. The Critical Study of Language. Londres: Longman, 233-252.

Firestone, Amy

2017 "Combinamos el quechua". Lengua e identidad de los jóvenes urbanos en el Perú. Lima: Instituto de Estudios Peruanos.

FLores, Nelson y Jonathan RosA

2015 "Undoing appropriateness: Raciolinguistic ideologies and language diversity in education". Harvard Educational Review. 85, 2, 149-171. https://doi.org/10.17763/0017-8055.85.2.149

García, Ofelia

2009 Bilingual education in the $21^{\text {st }}$ century. Malden / Oxford: Wiley-Blackwell.

Giroux, Henry

1992 Teoría y resistencia en educación. México: Siglo XXI.

GuMPERZ, John J.

1982 "The sociolinguistics of interpersonal communication". En Discourse Strategies. Cambridge: Cambridge University Press, 9-37. https://doi.org/10.1017/cbo9780511611834.004

Halliday, Michael

1994 [1985] An Introduction to Functional Grammar. Nueva York: Oxford University Press. 
Andrade y Zavala • De la lingüística a las aulas: ideologías en la educación peruana 113

Heller, Monica

2007 Bilingualism: A Social Approach. Nueva York: Palgrave. https://doi.org/10.1057/9780230596047

Heller, Monica y Marilyn Martin-Jones (eds.)

2001 Voices of authority. Education and Linguistic Difference. Londres: Routledge.

HildebrandT, Martha

1949 El español en Piura. Ensayo de dialectología peruana. Tesis de doctorado en Letras. Lima: Universidad Nacional Mayor de San Marcos.

Hymes, Dell

1974 Foundations in Sociolinguistics: An Ethnographic Approach. Filadelfia: University of Pennsylvania Press. https://doi. org/10.4324/9781315888835

IRVINE, Judith

1989 “When Talk Isn't Cheap: Language and Political Economy”. American Ethnologist. 16, 248-267. https://doi.org/10.1525/ ae.1989.16.2.02a00040

IRVINE, Judith T. y Susan GAL

2000 "Language ideology and linguistic differentiation". En Regimes of language: Ideologies, polities, and identities. Ed., Paul V. Kroskrity. Santa Fe: School of American Research Press, 35-84.

Ivanič, Roz y Wendy Moss

2004 "La incorporación de las prácticas de escritura de la comunidad en la educación”. En Escritura y sociedad. Nuevas perspectivas teóricas y etnográficas. Eds.,Virginia Zavala, Mercedes NiñoMurcia y Patricia Ames. Lima: Red para el Desarrollo de las Ciencias Sociales en el Perú, 211-246.

JiMÉNEZ BORJA, José

1931 El idealismo en la lingüistica y su derivación metodológica. Lima: Minerva.

1940 Composición literaria (preceptiva). Lima: Librería Peruana.

1973 “Sobre 'Piel o sombra amada' por Luis Hernán Ramírez”. Boletín de la Academia Peruana de la Lengua. 8, 135-136. 
2005 [1941] "El problema del bilingüismo en el Perú”. En José Jiménez Borja. Crítico y maestro de lengua. Ed., Carlos Eduardo Zavaleta. Lima: Universidad Católica Sedes Sapientiae / Academia Peruana de la Lengua / Fondo Editorial de la Universidad Nacional Mayor de San Marcos, 297-303. El artículo fue originalmente publicado en Letras 19, 169-179.

2005 [1955] "Fines de la enseñanza del castellano y la literatura en el Perú". En José Jiménez Borja. Crítico y maestro de lengua. Ed., Carlos Eduardo Zavaleta. Lima: Universidad Católica Sedes Sapientiae / Academia Peruana de la Lengua / Fondo Editorial de la Universidad Nacional Mayor de San Marcos, 277-286. El texto fue originalmente publicado por la Facultad de Educación de la Universidad Nacional Mayor de San Marcos.

KRESS, Gunther

2001 "From Saussure to Critical Sociolinguistics. The turn towards a social view of language". En Discourse Theory and Practice: A Reader. Ed., Margaret Wetherell, Stephanie Taylor y Simeon Yates. Londres: Sage / Open University, 29-38.

Kroskrity, Paul V.

2010 "Language ideologies. Evolving perspectives". En Society and language use. Eds., Jürgen Jaspers, Jan-Ola Óstman y Jeff Verschueren. Ámsterdam / Filadelfia: John Benjamins, 192-211. https://doi.org/10.1075/hoph.7.13kro

LABOV, William

1972 Language in the Inner City: Studies in the Black English Vernacular. Filadelfia: University of Pennsylvania Press.

LEEMAN, Jennifer

2015 "Heritage language education and identity in the United States”. Annual Review of Applied Linguistics. 35, 100-119. https://doi.org/10.1017/S0267190514000245

López, Luis Enrique

1990 "El bilingüismo de los unos y los otros: diglosia y conflicto lingüístico en el Perú”. En. Diglosia linguo-literaria y educación en el Perú. Homenaje a Alberto Escobar. Eds., Enrique Ballón Aguirre y Rodolfo Cerrón-Palomino. Lima: Consejo Nacional de Ciencia y Tecnología, 91-128. 
MARX, Karl y Friedrich ENGELS

1968 La ideología alemana. Montevideo: Pueblos Unidos.

Matras, Yaron

2009 Language Contact. Cambridge / Nueva York: Cambridge University Press.

Mesía, Ylse

2017 "Ideologías lingüísticas y racialización: un estudio con alumnos de secundaria en colegios limeños”. En Racismo y lenguaje. Eds., Virginia Zavala y Michele Back. Lima: Fondo Editorial de la Pontificia Universidad Católica del Perú, 151183.

Milroy, James y Lesley Milroy

1999 "Prescription and Standardisation". En Authority in Language: Investigating Standard English. Nueva York: Routledge, 1-23.

Moreno FernándeZ, Francisco

1998 Principios de sociolingüística y sociología del lenguaje. Barcelona: Ariel.

Pérez Silva, Jorge Iván y Virginia Zavala

2010 “Aspectos cognitivos e ideológicos del motoseo en el Perú". Ponencia presentada al V Congreso Internacional de la Lengua Española. Valparaíso: Centro Virtual Cervantes. Consultado: s/f. <http://congresosdelalengua.es/valparaiso/ponencias/ lengua_educacion/perez_zavala.htm $>$.

Phillipson, Robert

1992 Linguistic Imperialism. Oxford: Oxford University Press.

RAMírez, Luis Hernán

1969 Estructura y funcionamiento del lenguaje. Lima: Ultra.

2003 El español amazónico hablado en el Perú. Hacia una sistematización de este dialecto. Lima: Juan Gutemberg.

RosA, Jonathan Daniel

2016 "Standardization, racialization, languagelessness: Raciolinguistic ideologies across communicative contexts". Journal of Linguistic Anthropology. 26, 2, 162-183. https://doi. org/10.1111/jola.12116 
RosA, Jonathan y Christa BURDICK

2017 "Language ideologies". En The Oxford Handbook of Language in Society. Eds., Ofelia García, Nelson Flores y Massimiliano Spotti. Oxford: Oxford University Press, 103123.

SIEGEL, Jeff

2006 "Language ideologies and the education of speakers of marginalized language varieties: Adopting a critical awareness approach”. Linguistics and Education. 17, 2, 157-174. https:// doi.org/10.1016/j.linged.2006.08.002

VAN LeEUwEN, Theo

1996 “The representation of social actors". En Texts and practices. Readings in Critical Discourse Analysis. Eds., Carmen Rosa Caldas-Coulthard y Malcolm Coulthard. Londres: Routledge, 32-70.

WoOlard, Kathryn

2012 "Las ideologías lingüísticas como campo de investigación". En Ideologías lingüisticas. Práctica y teoría. Eds., Bambi B. Schieffelin, Kathryn Woolard y Paul V. Kroskrity. Madrid: Los Libros de la Catarata,19-69.

Zavala, Virginia y Gavina CóRdova

2010 Decir y callar. Lenguaje, equidad y poder en la Universidad peruana. Lima: Fondo Editorial de la Pontificia Universidad Católica del Perú.

Recepción: 26/02/2018

Aceptación: 21/05/2018 